\title{
Scrotal calcinosis
}

\section{Alaoui Aicha Elharrouni, Zakia Douhi, Samia Mrabat, Sara Elloudi, Hanane Baybay, Fatima Zahra Mernissi}

\author{
Department of Dermatology, University Hospital Hassan II, Fez, Morocco
}

Corresponding author: Dr. Alaoui Aicha Elharrouni, E-mail: ealaouiaicha@gmail.com

Sir,

We report a case of 28-year-old man with no history of scrotal trauma, metabolic disorder, presented to asymptomatic scrotal nodules had grown in size and number. Three years ago, the patient noticed a solitary, hard, painless nodule. More nodules subsequently appeared and coalesced on the scrotum. Physical examination revealed seven subcutaneous painless, firm nodules measuring $1-2 \mathrm{~cm}$ in diameter on the anterior scrotum (Figs. la and lb). There were no areas of ulceration, inguinal adenopathy, penile lesions, or urethral discharge. No inflammatory lesions surrounding the nodules were observed. The patient's blood and urine test results calcium, phosphorus were normal. We diagnosed these nodules with idiopathic scrotal calcinosis. A complete resection of the lesions was performed, and pathological examination confirmed scrotal calcinosis.

Scrotal calcinosis (SC) is a rare and benign condition. It usually gives rise to few symptoms, and the impact is mainly functional and aesthetic.SC occurs mainly between 20 and 40 years of age [1]. There are three types of scrotal calcinosis. One is the secondary type, as a result of hypercalcemia or hyperphosphatemia as may. Another is the dystrophic type with normal serum levels of calcium and phosphorus, but local inflammation promote calcium deposit formation. Otherwise, the condition is considered idiopathic type, the pathogenesis is not well understood $[2,3]$. The diagnosis is clinical, characterized by multiple, calcified and painless nodules of the scrotal skin [4]. Generally, scrotal calcinosis is a benign condition and surgical intervention is only made in the context of symptomatically or aesthetical reasons. A complete excision prevents recurrence [4,5]. Psychological support is required in association with surgery because the lesions are benign and concern an intimate part of the body.

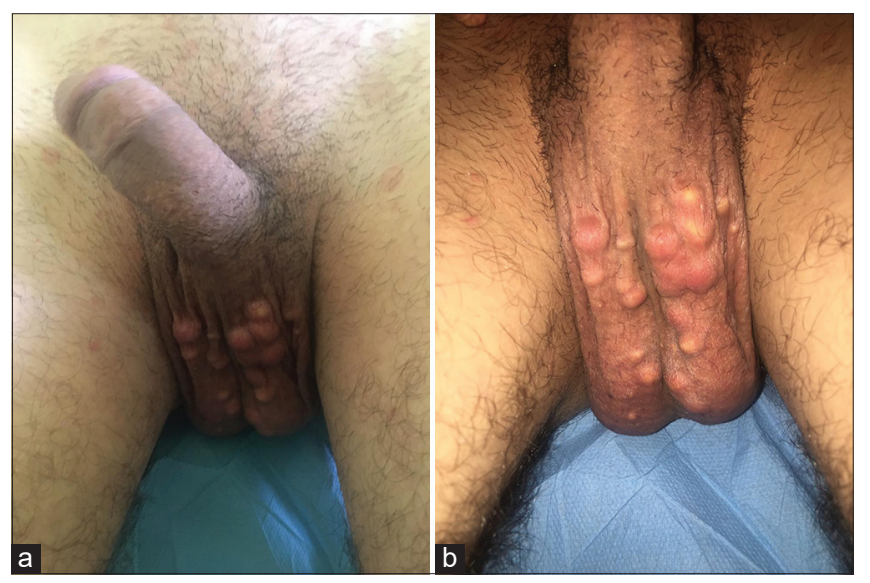

Figure 1: $(a$ and b) A 28 year-old male came in dermatology for multiple painless nodules involving the wholeof the scrotum.

\section{Consent}

The examination of the patient was conducted according to the Declaration of Helsinki principles.

\section{REFERENCES}

1. Sharma R, Maheshwari V. Scrotal calcinosis: idiopathic or dystrophic?. Dermatol Online J. 2010;16:5.

2. Insel M, Swenson S. Scrotal Calcinosis. J GenIntern Med. 2016;31:1104.

3. Khallouk A, Yazami OE, Mellas S, Tazi MF, El Fassi J, Farih MH. Idiophathic scrotal calcinosis: a non-elucidatedpathogenesis and itssurgicaltreatment. RevUrol. 2011;13:95-7.

4. Hoşcan MB, Akkaya H, Tunçkıran A, Durusoy C. Massive idiopathic scrotal calcinosis. Urology. 2012;80:71-2.

5. YuyucuKarabulut Y, Kankaya D, Şenel E, Dölek Y, Uslu A, Sertçelik A. Idiopathic scrotal calcinosis: the incorrect terminology of scrotal calcinosis. G ItalDermatolVenereol.2015;150:495-9.

Copyright by Alaoui Aicha Elharrouni, et al. This is an open-access article distributed under the terms of the Creative Commons Attribution License, which permits unrestricted use, distribution, and reproduction in any medium, provided the original author and source are credited.

Source of Support: Nil, Conflict of Interest: None declared. 